\title{
Analysing Probability Teaching Practices in Primary Education: What Tasks Do Teachers Implement?
}

\author{
Claudia Vásquez ${ }^{1, *(1)}$ and Ángel Alsina ${ }^{2}$ (1) \\ 1 Campus Villarrica, Pontificia Universidad Católica de Chile, Villarrica 4930445, Chile \\ 2 Departament of Subject-Specific Didactics, Universitat de Girona, 17004 Girona, Spain; angel.alsina@udg.edu \\ * Correspondence: cavasque@uc.cl
}

check for updates

Citation: Vásquez, C.; Alsina, Á.

Analysing Probability Teaching

Practices in Primary Education: What Tasks Do Teachers Implement? Mathematics 2021, 9, 2493. https:// doi.org/10.3390/math9192493

Academic Editor: Ángel Alberto Magreñán

Received: 15 September 2021

Accepted: 2 October 2021

Published: 5 October 2021

Publisher's Note: MDPI stays neutral with regard to jurisdictional claims in published maps and institutional affiliations.

\begin{abstract}
This study analyses probability tasks proposed by primary education teachers to promote probabilistic literacy. To this end, eight class sessions at various levels of the Chilean educational system were recorded on video and analysed through the "probability tasks" dimension from the “Observation Instrument for Probability Classes" (IOC-PROB), which includes five components: use of resources, probabilistic contexts, cognitive challenge, procedures and strategies, and probability meanings. The results show that probability tasks focus mainly on technical knowledge, causing the probability class to become an arithmetic class in which only formulas are applied, mechanically and with no meaning. As a result, we see no use of technological resources, a low use of physical materials, and an absolute predominance of solving decontextualised exercises. We conclude that it is necessary to enhance the probability teaching practices based on lesson plans that consider a wide variety of resources and contexts to gradually advance towards a representation of probabilistic knowledge that relies on conventional procedures and notations.
\end{abstract}

Keywords: teaching probability; probability tasks; probability literacy; teaching evaluation; lesson plans; professional teacher development

\section{Introduction}

Teaching school curriculum subjects requires a wide range of knowledge at every stage, ranging from knowledge of the content to be taught, to knowledge about how to teach it [1].

This paper focuses on the mathematical knowledge and, more specifically, on the teaching practices of in-service primary education teachers to teach probability. In particular, in this study we have focused on the knowledge in action of these teachers since, according to Hoover [2], it is beneficial to ask about the knowledge that teachers bring to bear in their teaching practices when presenting a certain mathematical topic. This is because knowing how teachers use this knowledge in the classroom is very useful for teacher trainers as they work to help teachers build, develop, and improve the professional knowledge needed to teach mathematics in the classroom [3]. This is especially relevant if we consider that teachers play a fundamental role in offering quality learning opportunities to their students $[4,5]$.

From this point of view, on the one hand, it is assumed that teachers should know many methods and how to implement them in the classroom, that is, they should be provided with criteria for knowing when, what, and why something is appropriate and reflect on it systematically [6]. On the other hand, and based on the Approach to Mathematics Lesson Plans (AMLP) [7], in the specific case of probability, teachers must be able to consider deliberate teaching sequences that regard various contexts and resources.

From this point of view, we are interested in analysing whether primary education teachers use this diversity of resources to teach probability since, without underestimating the other knowledge of the curriculum, it is assumed that in a changing world such as ours, 
where uncertainty is a constant, it is essential to have multiple tools to develop probability literacy. This is understood as "the ability to access, use, interpret and communicate information and ideas related to probability in order to participate in and effectively manage the demands of the functions and tasks that involve uncertainty and risk in the real world" (p. 4) [8].

Given this framework, special attention is paid to probability tasks posed by teachers in their classes. To this end, we rely on the model proposed by Vásquez et al. [9] to analyse the knowledge that teachers apply when teaching probability, which considers five aspects: probabilistic tasks, probabilistic reasoning, probabilistic connections, communication, and probabilistic language. Based on these aspects, Vásquez et al. [10] construct and validate the "Observation Instrument for Probability Classes" (IOC-PROB), which is used to analyse the elements that are specifically related to teaching probability, and which the teacher brings to bear during the instruction process.

Specifically, this study focuses on the "probability tasks" dimension, which includes the tasks, exercises, stochastic experiments, technological resources, etc., that teachers use to build their students' knowledge of probability. Based on this, our goal is to analyse the probability tasks presented in eight sessions of probability classes taught at different levels of the Chilean primary education system (6 to 14 years old).

\section{The Knowledge of Teachers to Teach Probability}

Although few models have been developed to characterise the professional knowledge of teachers to teach statistics and probability [11-13], since the end of the last century, some models that describe important aspects to consider have been developed. Moore [14], for example, notes that instruction in these topics requires joint activation between content, pedagogy, and technology, where the latter plays a fundamental role, as it is directly linked to content and pedagogy since it facilitates, through the use of technological tools, aspects such as: visualization, problem solving, the use of various representations, simulations, etc. Godino et al. [15] describe the disciplinary and didactic knowledge involved in teaching statistics and probability by considering the components of: (a) epistemological reflection; (b) transformation and adaptation of mathematical objects to a certain educational level; (c) knowledge of the difficulties, obstacles, and errors students face when learning, and of the strategies used to solve problems; and (d) exemplification of didactic situations, teaching methodologies, and didactic resources suitable for teaching statistics and probability, including technology. Later, Godino et al. [16] refined this model, creating what they call statistics pedagogical knowledge, which consists of five components (epistemological, cognitive, affective, interactional, and teaching resources and techniques). This model and these aspects would later evolve into the didactic-mathematical knowledge model [17].

Likewise, Burgess [18-21], based on some of the components of the MKT [22] and the model for describing statistical thinking proposed by Wild and Pfannkuch [23], proposes that, given the unique nature of statistical education, which demands specific ways of thinking and reasoning, a model that distinguishes these differences from mathematical thinking in general is required [19]. Consequently, he suggests the TKSI (Teacher Knowledge of and for Statistical Investigations) model, which addresses the components in Figure 1.

In parallel, Lee and Hollebrands [24,25] developed a model called "Teachers' Technological Pedagogical Statistical Knowledge" (TPSK), which integrates the knowledge of the mathematics and science teacher regarding content, pedagogy, and the use of technology. This model, which is based on the work of Shulman [1], considers the components of: (a) conceptions about the meaning of teaching a specific subject through technology; (b) knowledge of strategies and representations in order to teach specific topics through technology; (c) knowledge related to the reasoning, understanding, and learning of students through the use of technology; and (d) knowledge of materials and curriculum in ways that integrate technology with student learning. 


\begin{tabular}{|c|c|c|c|c|c|}
\hline & & \multicolumn{4}{|c|}{ Statistical knowledge for teaching } \\
\hline & & \multicolumn{2}{|c|}{ Content knowledge } & \multicolumn{2}{|c|}{ Pedagogical content knowledge } \\
\hline & & $\begin{array}{l}\text { Common } \\
\text { knowledge of } \\
\text { content } \\
\text { (CKC) }\end{array}$ & $\begin{array}{l}\text { Specialized } \\
\text { knowledge of } \\
\text { content } \\
\text { (SKC) }\end{array}$ & $\begin{array}{l}\text { Knowledge of } \\
\text { content and } \\
\text { students } \\
\text { (KCS) }\end{array}$ & $\begin{array}{l}\text { Knowledge of } \\
\text { content and } \\
\text { teaching } \\
(\mathrm{KCT})\end{array}$ \\
\hline \multirow{5}{*}{ 息 } & Need for data & & & & \\
\hline & Transnumeration & & & & \\
\hline & Variation & & & & \\
\hline & Reasoning with models & & & & \\
\hline & $\begin{array}{c}\text { Integration of statistical } \\
\text { and contextual }\end{array}$ & & & & \\
\hline \multicolumn{6}{|c|}{ Investigative cycle } \\
\hline \multicolumn{6}{|c|}{ Interrogative cycle } \\
\hline & Dispositions & & & & \\
\hline
\end{tabular}

Figure 1. Components of the TKSI model [18] (p. 4). (Reprinted with permission from ref. [18]. Copyright 2006, ICOTS7.)

Additionally, Garfield, Ben-Zvi, and collaborators [26-29], in an effort to promote statistical reasoning and to develop skills in future teachers to teach statistics, propose six interrelated principles that make up the SRLE (Statistical Reasoning Learning Environment) model.

Based on the different models, such as those previously described, Vásquez et al. [9] present a model to analyse the knowledge that teachers employ when teaching probability from an early age (Figure 2), and which considers five aspects: probabilistic tasks, probabilistic reasoning, probabilistic connections, communication, and probabilistic language.

Aspect 1: probabilistic tasks. This aspect and its components refer to the problems, exercises, stochastic experiments, etc., used to build new knowledge associated with probability. These tasks seek to stimulate the development of probabilistic reasoning through exploration and reflection involving solutions to problems in which uncertainty is present, meaning they must pose challenging tasks that allow counteracting probabilistic reasoning biases. These tasks also show and relate the different meanings of probability.

Aspect 2: probabilistic reasoning. This aspect and its components refer to the ability to formulate, interpret, obtain, and validate statements in which uncertainty is present. Its purpose is to recognize situations that involve probability and to be able to model them while breaking with probabilistic biases, as well as with preconceived notions and beliefs.

Aspect 3: probabilistic connections. This aspect and its components refer to connecting the ideas, concepts, definitions, properties, and procedures associated with probability with other blocks of mathematical content. It also connects current ideas, concepts, definitions, properties, and procedures associated with chance and probability, with those of earlier and/or later school levels.

Aspect 4: probabilistic communication. This aspect and its components refer to the communication processes that involve interaction, negotiation, and dialogue in mathematics class to promote learning ideas, concepts, definitions, properties, and procedures associated with probability.

Aspect 5: probabilistic language. This aspect and its components refer to the multiple languages (verbal, numeric, symbolic, tabular, and graphic) linked to probability.

Subsequently, based on these aspects, Vásquez et al. [10] construct and validate the "Observation Instrument for Probability Classes" (IOC-PROB), which is used to analyse the elements that are specifically related to teaching probability, which the teacher makes use of when carrying out the instructional process. The goal is to advance towards an in-depth understanding of the nature and characteristics of the knowledge needed to teach probability, since the teaching and learning process is complex and "depends fundamentally on what happens in the classroom, based on how teachers and students interact with the curriculum" [30] (p. 17). 


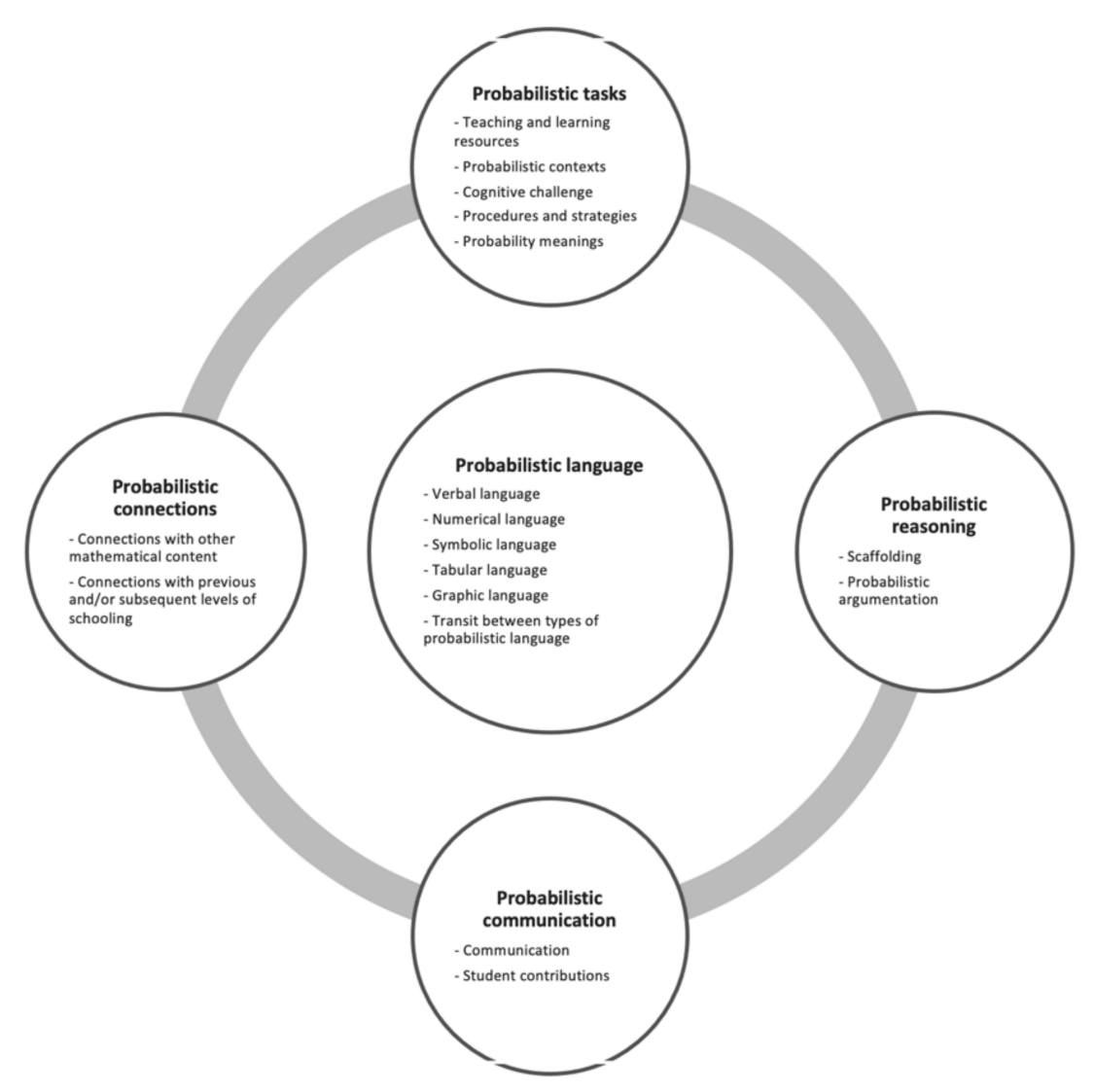

Figure 2. Aspects and components that characterise a model for effectively teaching probability from an early age (Adapted from [9] (p.7)). (Reprinted with permission from ref. [9]. Copyright 2019, CIVEEST.)

This study, as noted, focuses on the "probability tasks" dimension, which includes five components: teaching and learning resources; probabilistic contexts; cognitive challenge; procedures and strategies; and probability meanings.

\subsection{Teaching and Learning Resources}

This component seeks to describe the teaching and learning resources that teachers use to manage probability tasks they present to favour the development of probabilistic reasoning in their students. There are various authors and organizations that, for the specific case of probability, have promoted its teaching using various resources, such as manipulative materials and games, technological resources, etc. [31-37]. Batanero [36], for example, notes that "children are surrounded by chance from birth, in their games (casting lots, trivia games, cards, etc.)" (p. 5), alluding to the probability teaching.

\subsection{Probabilistic Contexts}

The purpose of this component is to analyse the context of probability tasks in which uncertainty is present (not only games of chance), giving meaning to their teaching, and that teachers use to motivate students' interest and promote the development of probabilistic reasoning. In the framework of probability, various authors propose the need to teach probability in contexts of several kinds, such as random experimentation, and social, personal, occupational, and scientific contexts [31,38,39]. In this regard, Hahn [39], for example, views the context as inescapable, since the data are defined as "numbers in context" [40]. Students are thus required to have the knowledge and skills to handle situations in their daily and professional lives in which probability is present and leads to decision-making in various contexts [41]. 


\subsection{Cognitive Challenge}

This component investigates the level of cognitive demand of the probability tasks proposed by the teacher, for the purpose of having students evoke and share their previous knowledge and experiences and link them with the new learning related to probability, which will allow students to assess the reorganisation of the new knowledge gained. Much of the learning that students acquire is conditioned by the type of tasks presented to them. However, not all tasks offer the same learning opportunities [42], and, contrary to what one might think, those tasks whose nature demands a high cognitive challenge are difficult to implement correctly, which results in their transformation to less-demanding tasks. From this perspective, Stein, Grover, and Henningsen [43] believe that a task can be classified according to its use: evaluative, if it is intended to obtain evidence regarding student learning, or instructional, if it is used to promote learning. The latter are the ones considered in this study since they play a mediating role between the students and the desired learning in relation to a certain mathematical idea. It should be noted that, according to Stein et al. [43], the cognitive demand of a task can vary based on its own characteristics and on how they are presented or executed (i.e., what is done by those who implement them). From this point of view, they propose a categorisation for mathematical tasks that reflects the type of thinking that is required to solve them, characterising mathematical tasks by levels of cognitive demand (memorisation, offline procedures, online procedures, and mathematics building) [44]. This taxonomy thus makes it possible to identify and select those tasks that promote reasoning in a way that they lead to a deep understanding of mathematics [45], in our case, tasks that promote the development of a deep understanding of probability.

\subsection{Procedures and Strategies}

This component focuses on the procedures understood as the strategies, algorithms, operations, and calculation techniques that teachers use or show their students to solve the probability tasks proposed. According to Gómez-Torres, Batanero, and Contreras [46], it is important to pay attention to the procedures and strategies associated with probability and how they relate to the meanings of probability, and which are addressed either implicitly or explicitly in the various probability tasks presented. These procedures can alert one to incorrect reasoning, heuristics, and biases that are present when learning probability.

\subsection{Probability Meanings}

The purpose of this component is to investigate the meanings (intuitive, frequency, classical, subjective, and axiomatic) of probability that are present in the probability tasks posed by teachers. This is relevant since, within the framework of their own professional development, all teachers concerned with improving how probability is learned in their classrooms should be aware of its different meanings. Otherwise, it would be difficult to understand the obstacles faced by students [47], who, in their process of building and learning the concepts related to this content block, "will encounter the same paradoxes and counterintuitive situations that appeared in the historical development of the calculation of probabilities" [48] (p. 28). According to Batanero [48], in the context of school mathematics, the intuitive, classical, frequency, subjective, and axiomatic meanings of probability all coexist. These meanings "implicitly determine the behaviours and responses of students when faced with situations of chance in which they must put their probabilistic intuitions and knowledge into practice" [49] (p. 20). Therefore, classroom practices should allow students to gradually build up their mathematical knowledge of probability from their probabilistic intuitions until they achieve an integrated view of probability from its multiple meanings [49]. In this sense, it is essential that throughout the educational stage, the teaching of probability is not limited exclusively to one of its meanings; on the contrary, it must be taught using an integrated approach based on its multiple meanings. 


\section{Method}

This study relies on a qualitative approach, specifically, on a study of multiple cases [50], and it is descriptive, since it seeks to describe and understand in depth the knowledge that the teachers who comprise the case study exhibit when teaching probability [51].

\subsection{Participants}

The study focused on the mathematics classes of eight Chilean primary education teachers (Table 1).

Table 1. Characterisation of the case studies.

\begin{tabular}{ccccc}
\hline $\begin{array}{c}\text { Case } \\
\text { Study }\end{array}$ & Gender & $\begin{array}{c}\text { Years of Experience } \\
\text { in the Classroom }\end{array}$ & $\begin{array}{c}\text { Grade in Which the } \\
\text { Class Is Taught }\end{array}$ & $\begin{array}{c}\text { School and Type of } \\
\text { Dependency }\end{array}$ \\
\hline 1 & Female & 13 & 1st grade & School 1, public \\
2 & Male & 38 & 2nd grade & School 1, public \\
3 & Female & 37 & 3rd grade & School 1, public \\
4 & Female & 26 & 4th grade & School 3, private \\
5 & Female & 21 & 5th grade & School 2, public \\
6 & Female & 5 & 6th grade & School 4, subsidised \\
7 & Female & 8 & 7th grade & School 2, public \\
8 & Female & 14 & 8th grade & School 4, subsidised \\
\hline
\end{tabular}

These teachers were selected based on the following criteria: (a) they have at least 5 years of experience teaching mathematics at any level of primary education; (b) they are recognised and recommended by their peers and supervisors for their good mathematics teaching practices; (c) they have good mathematics teacher performance reviews; (d) they constantly take part in refresher activities involving the teaching of mathematics; (e) they have taught probability more than once in the last 3 years; and (f) their students have exhibited good mathematics performance in local and national tests.

It is worth mentioning that the teachers participating in the study work in different educational institutions (public, private, and subsidised) in different cities in the south of Chile.

\subsection{Description of the Class Sessions}

This study considers eight classroom sessions that were videotaped in 2015-2016, and that specifically address topics related to the subject of probability (Table 2). Each session was 90 min long. The classes were recorded using an audio recorder hung around the teacher's neck and a video camera that recorded the teacher and the entire group. The camera was placed in a corner of the room, and the board and as many students as possible were framed in the shot. During the recording, the person filming was aware at all times of what was happening in the room in case it was necessary to pan or zoom the camera to better record what was happening. The camera stayed on the teacher (who is always the focus of the study), framing as many students as possible and zooming to record the teacher's interactions with one or more students or to focus on the worksheets, when one or more students were explaining something written on them. 
Table 2. Characterisation of the class sessions analysed.

\begin{tabular}{|c|c|}
\hline Grade & Learning Objective of the Class Session Analysed \\
\hline $\begin{array}{l}\text { 1st grade } \\
(6-7 \text { years old })\end{array}$ & $\begin{array}{l}\text { Students will be able to recognise chance and randomness when playing } \\
\text { dice and coin games. }\end{array}$ \\
\hline $\begin{array}{l}\text { 2nd grade } \\
(7-8 \text { years old })\end{array}$ & Students will be able to record results of random games. \\
\hline $\begin{array}{l}\text { 3rd grade } \\
(8-9 \text { years old })\end{array}$ & $\begin{array}{l}\text { Students will be able to identify and participate in random games by } \\
\text { recording data in a tally table. }\end{array}$ \\
\hline $\begin{array}{l}\text { 4th grade } \\
(9-10 \text { years old })\end{array}$ & Students will be able to perform randomised experiments. \\
\hline $\begin{array}{l}\text { 5th grade } \\
(10-11 \text { years old })\end{array}$ & $\begin{array}{l}\text { Students will be able to compare probabilities of occurrence of different } \\
\text { events without calculating them. }\end{array}$ \\
\hline $\begin{array}{l}\text { 6th grade } \\
(11-12 \text { years old })\end{array}$ & $\begin{array}{l}\text { Students will be able to speculate about the trend of the results obtained in } \\
\text { random situations. }\end{array}$ \\
\hline $\begin{array}{l}\text { 7th grade } \\
(12-13 \text { years old })\end{array}$ & $\begin{array}{l}\text { Students will be able to describe sample spaces of an experiment. } \\
\text { Students will be able to analyse experiments through relative frequency. }\end{array}$ \\
\hline $\begin{array}{l}\text { 8th grade } \\
\text { (13-14 years old) }\end{array}$ & $\begin{array}{l}\text { Students will be able to use the tree diagram and the multiplicative } \\
\text { principle for solving probability problems. }\end{array}$ \\
\hline
\end{tabular}

\subsection{Analysis Instrument}

In order to analyse how probability is taught in primary education, we relied, as indicated, on the "Observation Instrument for Probability Classes" (IOC-PROB) [10]. This instrument depends on the work of Vásquez et al. [9] and was constructed using a closed guideline method, based on a rubric that allows gathering evidence on the mathematical knowledge that the teacher brings to bear when teaching probability. Specifically, given the goal of this study, we focused on the "probability tasks" aspect; that is, on problems, exercises, stochastic experiments, etc., that promote reasoning through exploration and reflection, that relate the different meanings of probability, and that counteract biases in probabilistic reasoning in situations of uncertainty. To analyse this aspect, we considered the set of components associated with this aspect and their respective levels (Table 3).

Table 3. Components and levels of the "probability tasks" dimension IOC-PROB (Adapted from [10]). (Reprinted with permission from ref. [10]. Copyright 2020, Enseñanza De Las Cienc.)

\begin{tabular}{|c|c|}
\hline Components & Levels \\
\hline $\begin{array}{l}\text { Teaching-learning } \\
\text { resources: real } \\
\text { situations, physical } \\
\text { materials, games, } \\
\text { technology, } \\
\text { textbooks, etc. }\end{array}$ & $\begin{array}{l}\text { Low: uses only one resource and does not adequately manage the } \\
\text { developing probabilistic reasoning of the students. } \\
\text { Medium low: uses at least two resources but does not use them to } \\
\text { adequately manage the developing probabilistic reasoning of the students. } \\
\text { Medium high: uses at least two resources and uses one to adequately } \\
\text { manage the developing probabilistic reasoning of the students. } \\
\text { High: uses at least two resources and uses both to adequately manage the } \\
\text { developing probabilistic reasoning of the students. }\end{array}$ \\
\hline $\begin{array}{l}\text { Probabilistic } \\
\text { contexts: social, } \\
\text { personal, } \\
\text { occupational, } \\
\text { scientific, or related } \\
\text { to experimentation } \\
\text { and games of } \\
\text { chance. }\end{array}$ & $\begin{array}{l}\text { Low: proposes probability tasks involving contexts related exclusively to } \\
\text { experimentation or games of chance. } \\
\text { Medium low: proposes probability tasks based mainly on experimentation } \\
\text { and games of chance, and anecdotally proposes other contexts familiar to } \\
\text { the student. } \\
\text { Medium high: proposes probability tasks involving various probabilistic } \\
\text { contexts familiar to the student but focuses on two different contexts. } \\
\text { High: proposes probability tasks involving diverse contexts familiar to the } \\
\text { student that, in addition to experimentation and games of chance, also } \\
\text { include social, personal, occupational, and scientific contexts. }\end{array}$ \\
\hline
\end{tabular}


Table 3. Cont.

\begin{tabular}{|c|c|}
\hline Components & Levels \\
\hline $\begin{array}{l}\text { Cognitive } \\
\text { challenge: } \\
\text { consistency } \\
\text { between existing } \\
\text { knowledge and } \\
\text { new content. }\end{array}$ & $\begin{array}{l}\text { Low: proposes tasks that do not pose a challenge to students, since they do } \\
\text { not require them to evoke their existing knowledge to build new learning } \\
\text { linked to chance and probability. } \\
\text { Medium low: proposes tasks that encourage students to evoke and share } \\
\text { their existing knowledge, but they are not adequately linked to the new } \\
\text { learning related to chance and probability. } \\
\text { Medium high: proposes tasks that encourage students to evoke and share } \\
\text { their existing knowledge and adequately link it to the new learning related } \\
\text { to chance and probability but does not propose tasks to assess the } \\
\text { reorganisation of the new knowledge gained. } \\
\text { High: proposes tasks that encourage students to evoke and share their } \\
\text { existing knowledge, linking them to new learning related to chance and } \\
\text { probability; and proposes tasks to assess the reorganisation of the new } \\
\text { knowledge gained. }\end{array}$ \\
\hline $\begin{array}{l}\text { Procedures and } \\
\text { strategies: } \\
\text { algorithms, } \\
\text { operations, } \\
\text { calculation } \\
\text { techniques, etc. }\end{array}$ & $\begin{array}{l}\text { Low: proposes probability tasks in which the same solution procedure } \\
\text { and/or strategy is always applied and/or adapted. } \\
\text { Medium low: proposes probability tasks in which a variety of solution } \\
\text { procedures and/or strategies are applied and/or adapted but does not } \\
\text { encourage students to reflect on them. } \\
\text { Medium high: proposes tasks in which it is possible to apply and/or adapt } \\
\text { a variety of procedures and/or strategies, which are used to promote } \\
\text { reflection on solving the probability tasks, but not to decide how and when } \\
\text { to use them. } \\
\text { High: proposes tasks in which it is possible to apply and/or adapt a } \\
\text { variety of procedures and/or strategies to promote reflection on solving } \\
\text { the probability tasks, as well as to decide how and when to use them. }\end{array}$ \\
\hline $\begin{array}{l}\text { Meanings of } \\
\text { probability: } \\
\text { intuitive, } \\
\text { frequency, classical, } \\
\text { subjective, and } \\
\text { axiomatic. }\end{array}$ & $\begin{array}{l}\text { Low: proposes probability tasks to show and explore only one of the } \\
\text { meanings of probability. } \\
\text { Medium low: proposes probability tasks to show and explore two of the } \\
\text { meanings of probability but does not promote reflection on them. } \\
\text { Medium high: proposes probability tasks to show, explore, reflect on, and } \\
\text { relate two of the meanings of probability. } \\
\text { High: proposes probability tasks to show, explore, reflect on, and relate at } \\
\text { least three of the meanings of probability. }\end{array}$ \\
\hline
\end{tabular}

\subsection{Coding and Analysis of Information}

As part of the analysis process, a systematic observation was performed [52], which is a type of analytical tool that involves two phases: coding and counting. The class sessions that comprise our analysis units were coded using the indicators contained in the instrument. The class videos were coded by external coders specialised in mathematics didactics for primary education, probability didactics, or in coding math classes in general.

To ensure the reliability of the coding, the three coders were instructed on the use of the instrument to train them to set aside their value judgments and thus reduce their interpretation and inference regarding what happens in the classroom [53]. To facilitate the coding process and the objectivity, the coders were provided with examples for each level, since, while it is true that the coder must abide by the definition of the different levels that make up each component, and not by the examples, these can provide support at times when making coding decisions. The coders then underwent a calibration process involving joint coding sessions and discussions of disagreements to standardise criteria, before engaging in individual coding processes, which allowed us to evaluate the levels of inter judged reliability. For the coding process, the coders had:

- findings record sheet: consists of a sheet that allows the coder to log descriptions of each session, which will be used as an input to determine the score assigned to each component, as per the pre-determined levels (level 1: low, level 2: medium low, 
level 3: medium high, and level 4: high). This sheet is also used to record general aspects, as well as data associated with the session (date, coder's name, teacher's name, course, name of the content involved).

- $\quad$ scoring record sheet for each component: consisting of a printed sheet in which the aspects, components, and levels to be coded are listed, and a column exists to record the scores associated with the presence (1) or absence (0) of each level. A code was also explicitly provided to record those chance moments during which an instruction process is observed that cannot be encoded using the levels established in the instrument, for which code 9 was designated.

\section{Results}

The results were grouped based on the categories that make up the aspect of the probabilistic tasks: teaching and learning resources, probabilistic contexts, cognitive challenge, procedures and strategies, and probability meanings.

\subsection{Teaching and Learning Resources}

This component seeks to determine what teaching and learning resources the instructor uses when teaching probability.

An analysis of all the class sessions, and considering the entire class, yielded the following results based on the four levels established in the instrument (Figure 3).

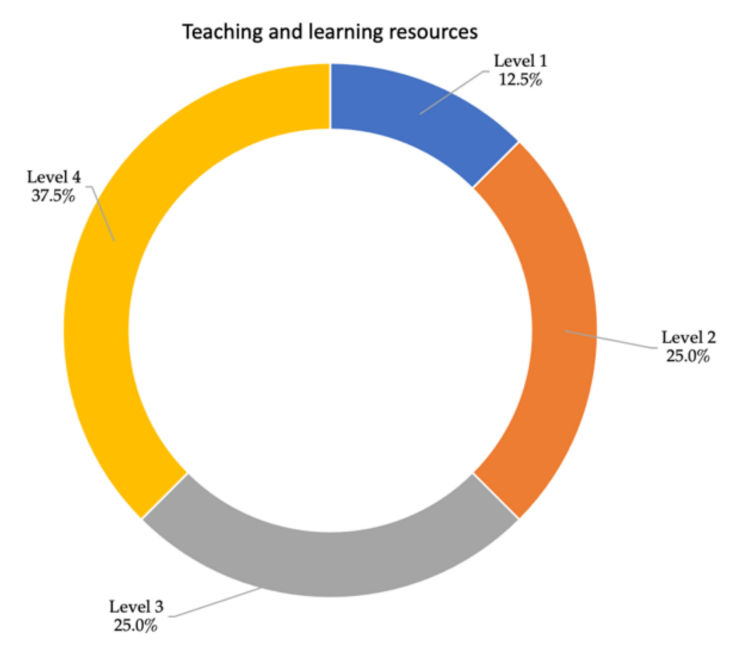

Figure 3. Teaching and learning resources by level.

Figure 3 shows that, in general, the largest proportion of teachers is at the high level $(38 \%)$ in terms of using teaching and learning resources to plan their probability lessons, meaning they use at least two resources. Only $12.5 \%$ are at the low level since they rely solely on one resource.

When these data are disaggregated to analyse each teacher's method, we see that the use of resources to teach probability receives the lowest scores-between levels 1 and 2-in the initial years of primary school. Starting with fourth grade, however, it moves to the medium high and high levels. Table 4 lists the resources used.

As we can see, the most used resource is the textbook, which is mostly used for students to practice and apply what they learned during the class; followed by random experiments with the use of manipulatives, such as dice and coins. The resource that is used the least is random experiments with roulette wheels, and everyday situations that are used to consider probability through situations that stem from actual situations familiar to the students. Only in one of the eight classes analysed was this approach used. Finally, in none of the classes did the instructors resort to the use of software to teach probability at these ages. 
Table 4. Teaching and learning resources used.

\begin{tabular}{cc}
\hline Resources & $\begin{array}{c}\text { Percentage of Use } \\
(\boldsymbol{n}=8)\end{array}$ \\
\hline Dice & $75 \%$ \\
Colored balls & $25 \%$ \\
Coins & $62.5 \%$ \\
Roulette & $12.5 \%$ \\
Software & $0 \%$ \\
Textbook & $87.5 \%$ \\
Other (board, PowerPoint presentation, videos, etc.) & $37.5 \%$ \\
\hline
\end{tabular}

\subsection{Probabilistic Contexts}

The goal of this component is to determine the contexts that the teacher uses when teaching probability.

Accordingly, an analysis of the classes shows (Figure 4) that many of the teachers present probability tasks in the low and medium low levels, meaning they rely on contexts linked to random experimentation and, very anecdotally, on other contexts, especially social and personal, that are familiar to the students. However, the presence of at least one context is always observed.

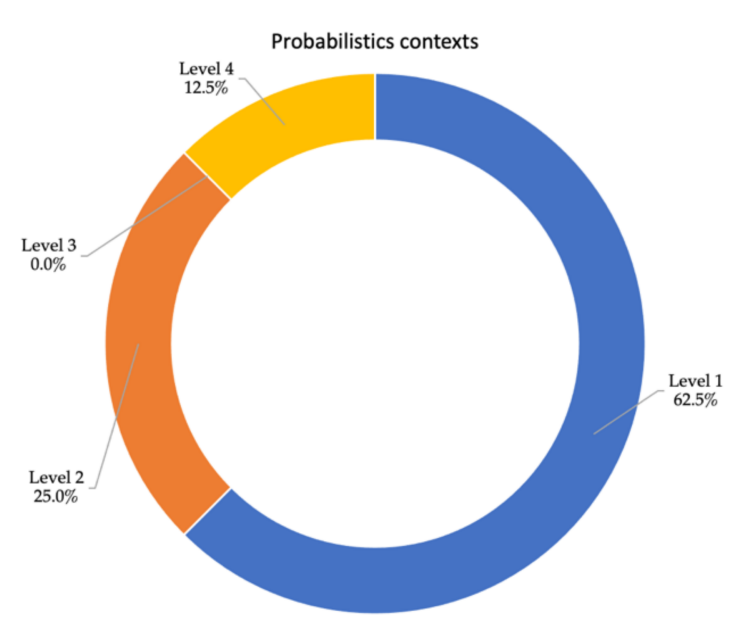

Figure 4. Probabilistic contexts by level.

If we focus on the contexts of the probability tasks given in each grade, it shows that the fifth grade has the most context, since, to compare the probabilities of different events without calculating them, the teacher proposes probability tasks with diverse contexts familiar to the students, as well as situations that involve randomised experiments. An example of this is the activity proposed by the teacher where, using various sheets with situations involving uncertainty (Figure 5), the students must discuss their probability of occurrence by identifying varying degrees of its likelihood, ranging from impossible to certain. As a result of this discussion and based on the diversity of opinions given by the students themselves, a scale is set up that allows for qualitatively assessing the opportunities of occurrence (Figure 6), where each degree of possibility implies a different level of uncertainty. 


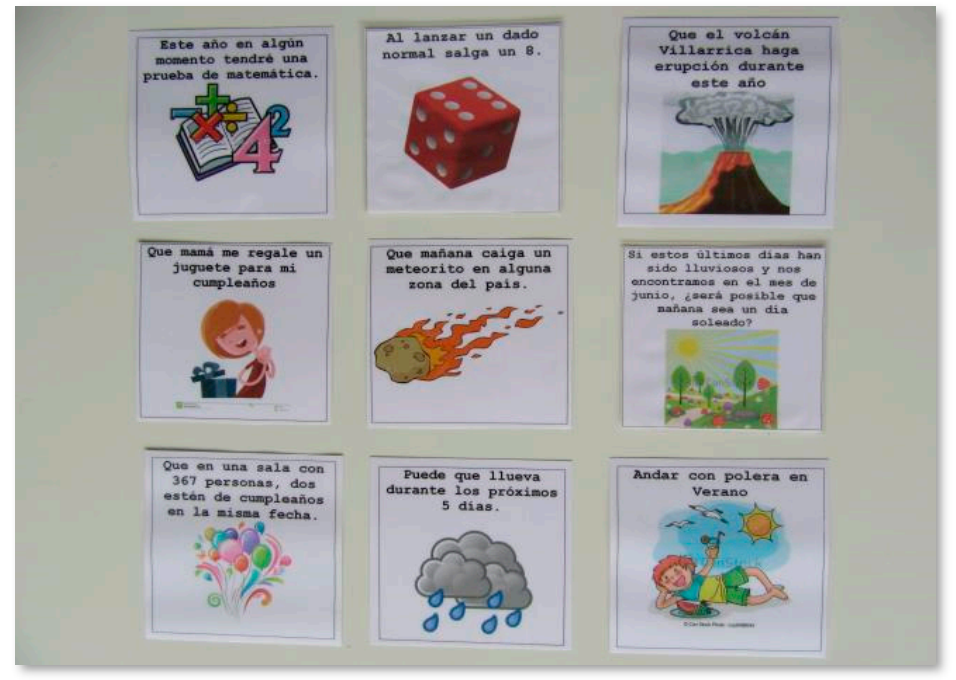

Figure 5. Image capture for 5th grade class.

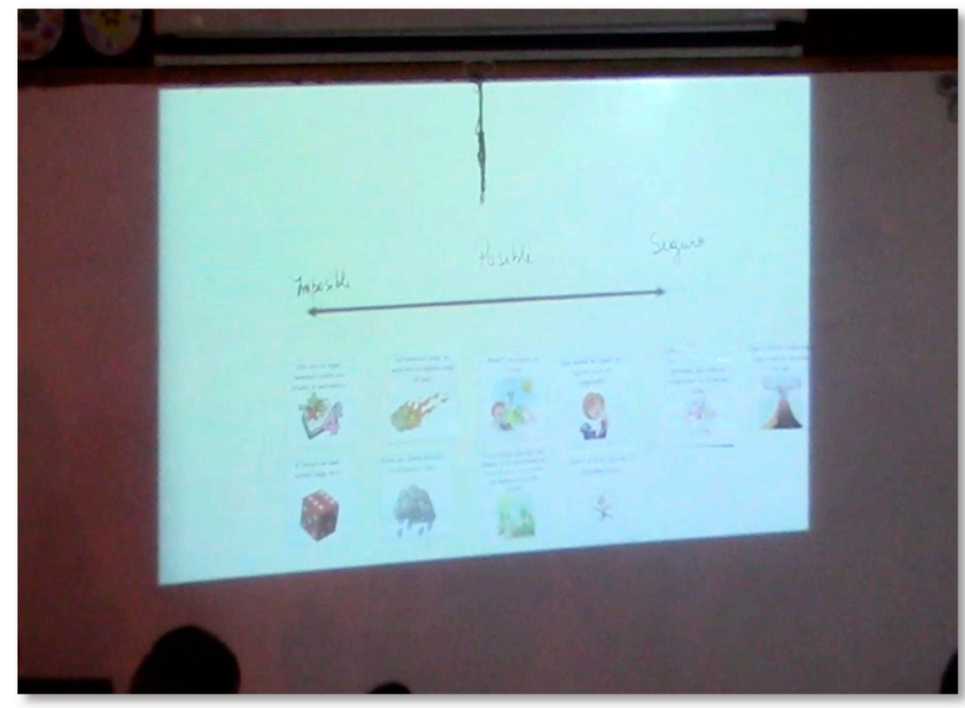

Figure 6. Image capture for 5 th grade class.

Regarding the contexts used in the probability tasks given, Table 5 shows that random experimentation is the most frequent context (75\%), even though the experiment is not always carried out using manipulatives; rather, the random experiment is often mentioned, and only work on probability calculation is involved. The low presence of social and personal contexts $(12.5 \%)$, as well as no presence of occupational and scientific contexts, should be stressed.

Table 5. Tasks' probabilistic contexts.

\begin{tabular}{cc}
\hline Probabilistic Contexts & $\begin{array}{c}\text { Percentage of Use } \\
(\boldsymbol{n}=\mathbf{8})\end{array}$ \\
\hline Random experiment & $75 \%$ \\
Social & $12.5 \%$ \\
Personal & $12.5 \%$ \\
Occupational & $0 \%$ \\
Scientific & $0 \%$ \\
\hline
\end{tabular}




\subsection{Cognitive Challenge}

This component investigates the cognitive challenge posed by the probability tasks that the teacher uses to promote probability learning.

Based on the analysis of the classes, Figure 7 shows that, in the class sessions analysed, the level of the probability tasks is predominantly medium high and medium low, with frequencies of $50 \%$ and $25 \%$, respectively. The remaining $37.5 \%$ is located at the extremes, that is, at a low or high level.

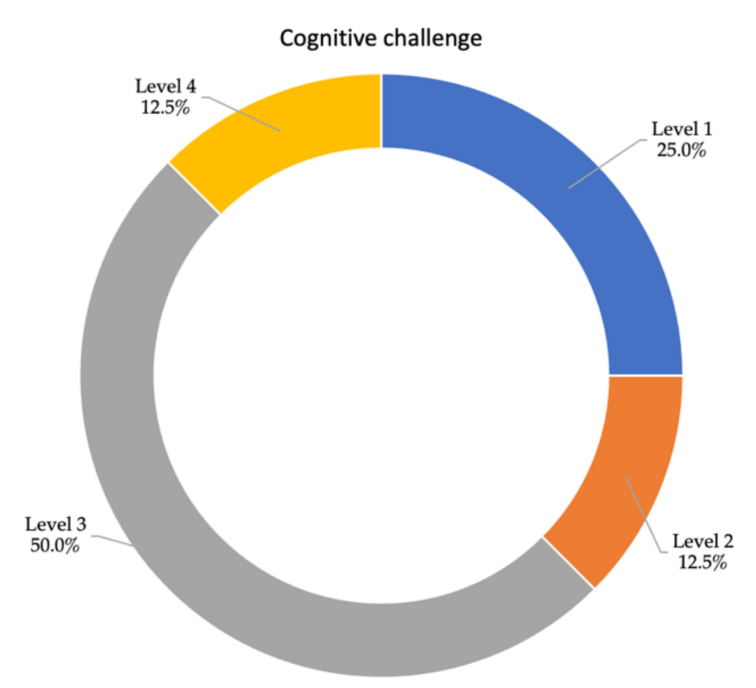

Figure 7. Cognitive challenge by levels.

When disaggregating the data by grade, we see variability in the levels associated with the cognitive challenge of the tasks proposed. For example, in the fourth grade, the teacher proposes tasks with a low cognitive challenge involving the conduct of random experiments. Specifically, the students must flip a coin 20 times and record the results in a frequency table (Figure 8). However, this ignores an analysis of important aspects involving the random experiment of tossing a coin, such as, for example, when a coin is tossed in the air, there are only two possible outcomes, heads or tails. Similarly, the student is not presented with conceptual ideas associated with probability, since no emphasis is placed on the fact that the result cannot be predicted in advance and will vary when the coin is flipped repeatedly. However, it is possible to observe a certain regularity in the results, a regularity that only emerges after many repetitions. There is also no reference made to how the proportion of flips that result in "heads" can be quite variable at the beginning, but as more and more tosses are made, it stabilizes, approaching the 0.5 ratio and staying at that value. It is thus said that the probability of "heads" is 0.5 , which means that the "heads" event occurs half the time after many tosses. By contrast, this task presents little ambiguity in terms of what to do and how.

A similar situation occurs in eighth grade, where the tasks are associated with the use of the tree diagram and the multiplicative principle. However, the tasks proposed by the fifth-grade teacher-with the purpose of having his students compare the probabilities of different events without calculating them-pose a high cognitive challenge, since they not only allow students to evoke and share their previous knowledge while linking it with new knowledge about probability, specifically, with the construction of the gradual scale of likelihood of occurrence (Figure 6), but it also lets them assess the reorganisation of the new knowledge gained. 


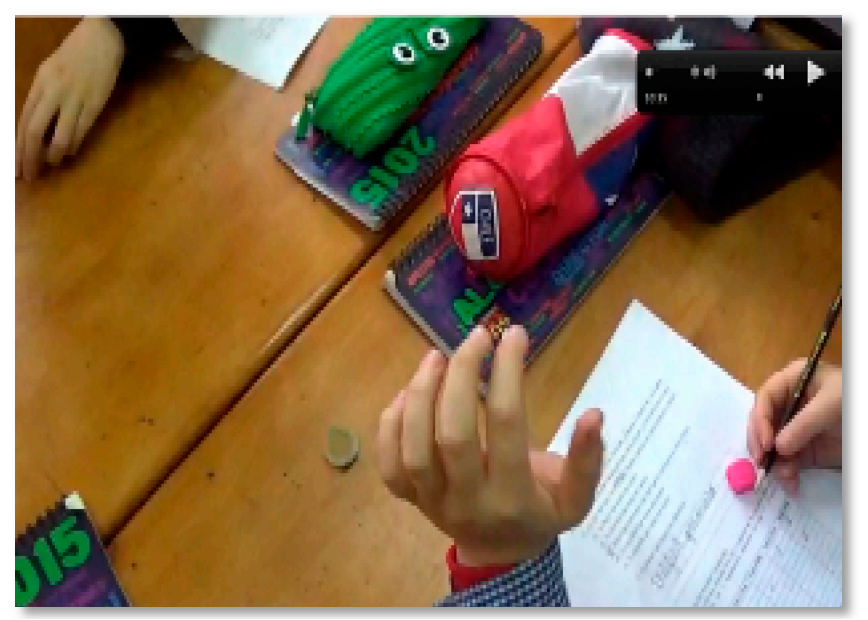

Figure 8. Image capture of 4th grade class.

\subsection{Procedures and Strategies}

This component seeks to determine which procedures and strategies the teacher uses, or teaches students to use, to solve the probability tasks proposed.

An analysis of the class sessions (Figure 9) shows that only in $12.5 \%$ of the classes analysed are tasks proposed that make it possible to apply a variety of resolution procedures.

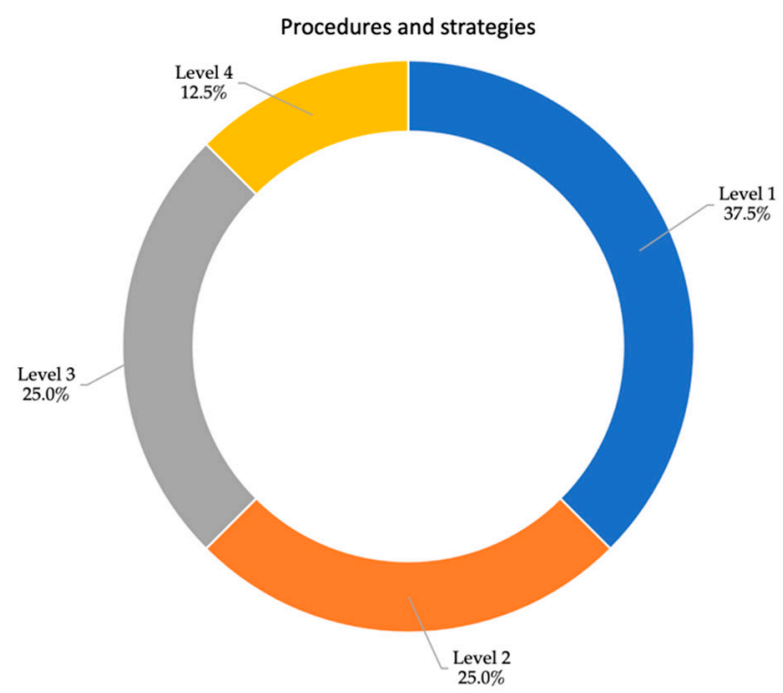

Figure 9. Procedures and strategies by level.

When analysing the data by grade, we see that the probability procedures used are mostly at the low and medium low level. In the 2nd and 3rd grade, although a variety of procedures are used, no support is provided for the students to decide how and when to use these procedures; it is only in the 5th grade that this topic is addressed.

Regarding the procedures used to solve the probability tasks proposed, Table 6 shows that the most commonly used $(87.5 \%)$ are the construction of a sample space, differentiation between favourable and unfavourable cases, and the application of Laplace's rule to simple experiments $(87.5 \%)$. However, this rule is applied very informally and without referring to the equiprobability principle of the events. Other procedures that are present in abundance $(75 \%)$ are the use of random generators (dice, coins, roulette wheels, etc.), and the repetition of random experiments to estimate the probability; although, the approximate nature of such an estimate is not acknowledged. Finally, relative frequencies are calculated based on observations or data. 
Table 6. Probabilistic procedures used in the tasks.

\begin{tabular}{cc}
\hline Probabilistic Procedures Used & $\begin{array}{c}\text { Percentage of Use } \\
(\mathbf{n = 8 )}\end{array}$ \\
\hline Manipulation of random generators & $75 \%$ \\
Distinguishing between random and deterministic phenomena & $12.5 \%$ \\
Recognising the unpredictability of an outcome & $37.5 \%$ \\
Recognising different types of events & $37.5 \%$ \\
Qualitative likelihood assessments & $37.5 \%$ \\
Qualitative comparison of possibilities & $37.5 \%$ \\
Analysis of games of chance & $12.5 \%$ \\
Sample space construction & $87.5 \%$ \\
Differentiating favourable and unfavourable cases & $87.5 \%$ \\
Distinguishing elementary equiprobable events & $12.5 \%$ \\
Comparing probabilities using proportional reasoning & $12.5 \%$ \\
Applying Laplace's rule to simple experiments & $87.5 \%$ \\
Repeating the same random experiment to estimate probabilities & $75 \%$ \\
Calculating relative frequencies from observations or data & $75 \%$ \\
Representing the frequency distribution in tabular or graphical form & $25 \%$ \\
Analyzing experiments where probability depends on personal information & $37.5 \%$ \\
\hline
\end{tabular}

The probability procedures that exhibit the lowest frequencies $(12.5 \%)$ are those related to distinguishing between random and deterministic phenomena, analysing games of chance, distinguishing elementary equiprobable events, and comparing probabilities using proportional reasoning.

\subsection{Probability Meanings}

This component investigates probability meanings that underlie the teachers' teaching practices.

Firstly, Figure 10 shows that the class sessions analysed are at a medium high level (50\%), since the teachers pose probability tasks that can be used to show, explore, reflect on, and relate two of the probability meanings.

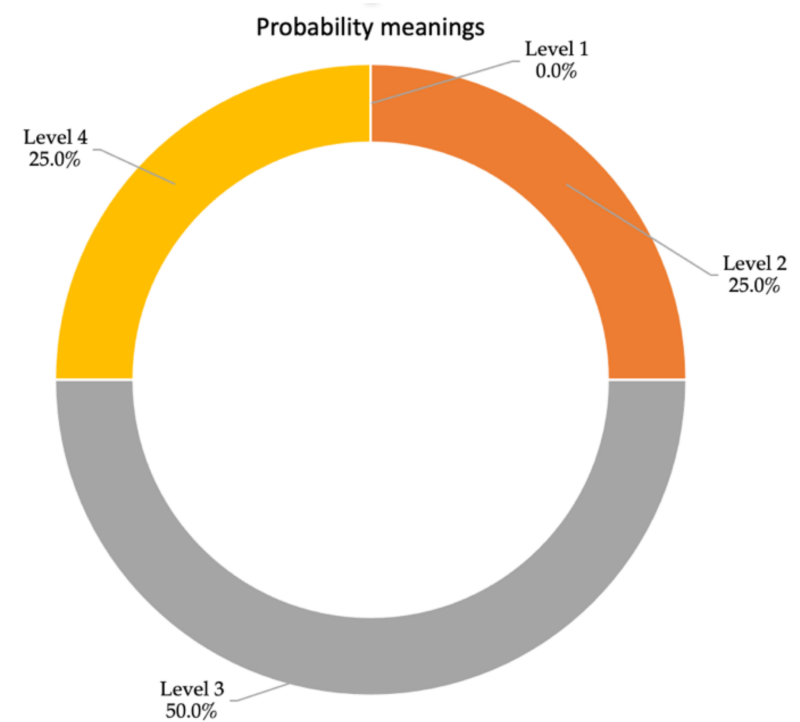

Figure 10. Probability meanings by level.

A grade-to-grade perspective shows that as each grade progresses, the probability tasks proposed increase in level in terms of probability meanings, and by the last two grades, teachers propose tasks that make it possible to relate at least three of the probability meanings. 
Now, when these data are disaggregated to look more closely at the probability meanings involved in the probability tasks proposed in each grade (Table 7), we see a predominance of the classical probability meaning that is strongly related to probability tasks which involve the Laplace's rule application. The meaning that receives less attention is the subjective one, which is only covered very tangentially in the last year of primary school.

Table 7. Probability meanings present in the class sessions.

\begin{tabular}{cc}
\hline Meanings of Probability & Percentage of Presence \\
& $(\boldsymbol{n}=\mathbf{8})$ \\
\hline Intuitive & $75 \%$ \\
Frequency & $75 \%$ \\
Classical & $87.5 \%$ \\
Subjective & $37.5 \%$ \\
\hline
\end{tabular}

To exemplify the different meanings of probability observed in the probability tasks, a summary of some of the practices observed is provided below.

In relation to the intuitive meaning, the seventh-grade teacher proposes various problem situations to introduce the calculation of probabilities in which students must first estimate and compare the likelihood of the occurrence of certain events. For example, according to the information presented in Figure 11, they are asked about the possible outcomes, as well as which one has the best chance of occurrence when the arrow is spun. Or, if forced to choose with eyes closed between seven orange cards and one green, are the events equally possible or not equally possible?

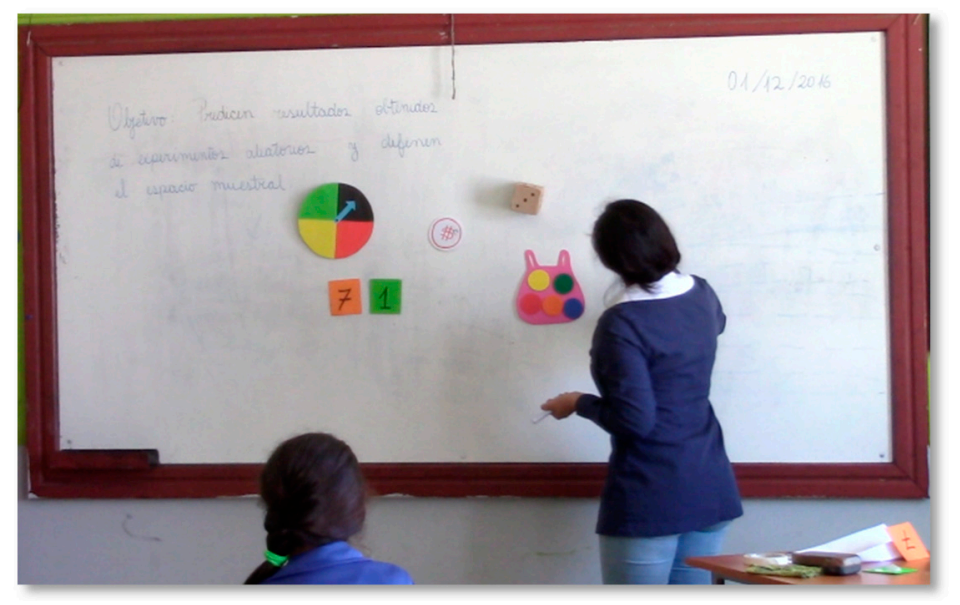

Figure 11. Image capture of 7th grade class.

Thus, starting with questions such as those mentioned above, the teacher asks students to decide and then associate the possibility of occurrence with different degrees of possibility, thereby introducing them to the notion of probabilities using an intuitive approach.

In relation to the frequency meaning, the sixth-grade teacher, for her students to conjecture about the trend of the results of tossing a coin, asks them the following question: What would happen if a coin was tossed 100 times? Which outcome is most likely, heads or tails? She then asks them to do the experiment of tossing the coin 100 times and records the results in a frequency table so they can determine the experimental likelihood of a heads and compare their prediction with the result of the experiment. Finally, she asks them to gather the results from the different work groups and tally the results of 3000 flips. It is based on this probability task that the teacher aims, using a frequency approach supported by the graphical representation of frequencies (Figure 12), to have the students understand that when the coin toss experiment is repeated a sufficiently large number of times under the same conditions, there comes a point when the relative frequencies 
stabilise and converge to the value 0.5 , which is the one that corresponds to the probability of occurrence.

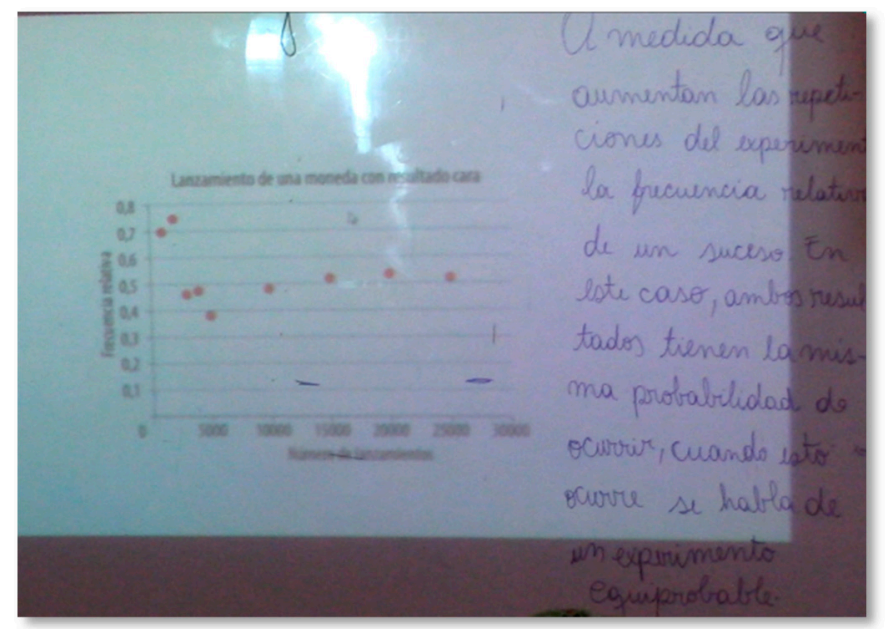

Figure 12. Image capture of 6 th grade class.

In relation to the classical meaning, by way of example, in the 5 th grade, we see that once probabilistic language is introduced and the qualitative scale of degrees of possibility of occurrence is identified, the students are given the following task to have them start calculating probabilities:

There are 3 bags with red and yellow balls like the ones I have given to each group (Figure 13). If you must take out a yellow ball to win a prize, without looking inside the bag, which one would you take out?

In which bag are you most likely to get a red ball? Why?

What is the likelihood of drawing a red ball from each of the bags?

How many balls, and of what colour, must be added to each bag so that in the three bags there is the same probability of getting a yellow bag?

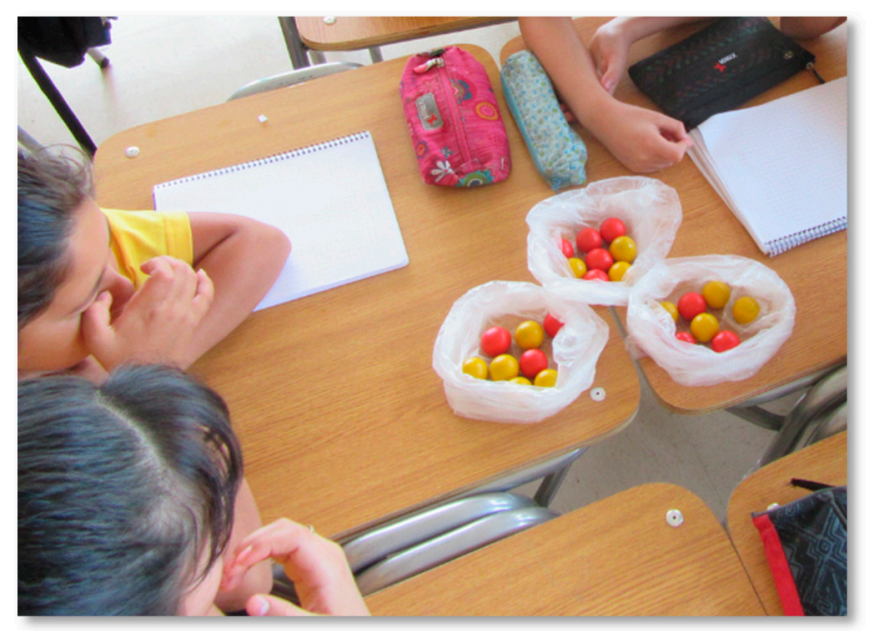

Figure 13. Image capture of 5 th grade class.

It is with this task that the teacher introduces students to the calculation of probabilities from a classical approach to probability.

Finally, with regards to subjective meaning, in the 5th grade, the tasks posed by the teacher to qualitatively assess the possibility of occurrence (Figure 5) initially address the subjective approach to probability, since some of the situations proposed focus on how the probability of occurrence can be affected (changed) based on the information available (the existing probabilities are adjusted by incorporating the new information available). 
Emphasis is also placed on analysing examples and previous experiences to adjust the existing odds based on new information.

\section{Discussion and Final Considerations}

This study has analysed the tasks presented by in-service primary education teachers during their classes on probability.

It is in this sense that Vásquez et al. [9] focused on developing a multidimensional view of teaching probability that gives us a greater understanding of the knowledge that the teacher uses during the teaching process. As indicated, the model developed by these authors considers five aspects: probability tasks, probabilistic reasoning, probabilistic connections, communication, and probabilistic language. Based on these aspects, Vásquez et al. [10] construct and validate the "Observation Instrument for Probability Classes" (IOC-PROB), which is used to analyse the elements that are specifically related to teaching probability, which the teacher brings to bear when carrying out the instructional process.

In relation to probability tasks, this tool includes five components: teaching and learning resources; probabilistic contexts; cognitive challenge; procedures and strategies; and meanings of probability. The data obtained in this study from the eight class sessions analysed have provided evidence regarding each of these components:

(1) Teaching and learning resources: it has been shown that the most utilised resource continues to be the textbook, followed by random experiments with the use of manipulatives, such as dice and coins, while the least used are real contexts and educational software. These data reveal, on the one hand, that teachers continue to rely mainly on textbooks as a resource to teach probability, which implies that students' learning opportunities are closely linked to the knowledge provided by these books [54]; on the other hand, they show that although certain manipulatives are used (dice and coins), other manipulatives, such as roulette wheels, along with games, are rarely used, and technological resources are not used, despite the guidance provided by various authors who promote the teaching of probability through these resources [31,32,34-37,55].

(2) Probabilistic contexts: in line with the data obtained from the first component of the probability tasks, which revealed that one of the teaching resources most used by the study participants is randomised experiments, the results of this second component have shown that random experimentation is the most common context; although, sometimes the experiment is only discussed, and the work focuses on calculating probabilities. The other contexts have either a low presence (social and personal contexts), or none, in the case of occupational and scientific contexts. This is a worrisome fact that goes against the recommendations of various authors who, as indicated, suggest the need to teach probability through a variety of contexts $[31,38,39,56]$, which consider real, relevant, and meaningful problems for students, such as, for example, those contexts linked to the pandemic derived from COVID-19 or to sustainability.

(3) Cognitive challenge: in the class sessions analysed, the probability tasks predominantly focused on the medium high and medium low levels in terms of cognitive demand, which means that the teachers either promote connections between previous knowledge and new knowledge, but without helping the students to reorganise them, or do not directly make these connections. In accordance with the approaches of authors such as Stein et al. [43] and Smith and Stein [44], among others, these results reveal that, in various cases, teachers miss opportunities to promote probabilistic reasoning, for example, which is one of the essential skills to ensure an in-depth understanding of mathematics [45].

(4) Procedures and strategies: the data obtained are worrying, since they have shown that the probabilistic procedures used are mostly at the low and medium low level, which implies monotony and a lack of reflection in probability classes. These data conflict with the approaches of Korthagen [6], who states that teachers should know 
multiple courses of action and how to apply them, meaning they should have criteria for knowing when, what, and why something is convenient, and be able to reflect on it systematically. A more detailed analysis has revealed that some of the most common procedures used by teachers are the construction of the sample space, the differentiation of favourable and unfavourable cases, the informal application of Laplace's rule in simple experiments, the use of chance generators (dice, coins, roulette, etc.), and the repetition of random experiments to estimate probability. Meanwhile, procedures aimed at distinguishing between random and deterministic phenomena, analysing games of chance, distinguishing elementary equiprobable events, and comparing probabilities using proportional reasoning, are less common. This study has thus shown that teachers tend to use procedures and strategies that promote the development of skills such as knowing and applying, and not so much other skills, such as reasoning [57].

(5) Probability meanings: in relation to this last component of probability tasks, the class sessions analysed are at a medium high level. This is because the teachers participating in the study have proposed probability tasks that can be used to show, explore, reflect on, and relate two of the probability meanings. However, a more detailed analysis has revealed that the most common meaning is the classical one, which is strongly related to probabilistic tasks that involve the Laplace's rule application. Conversely, the meaning that receives less attention is the subjective one. These results conflict with Vásquez and Alsina [47], who emphasise the essential nature of teaching probability in primary education in an integrated manner that considers its multiple meanings.

In conclusion, the results show that the probabilistic tasks focus mainly on technical knowledge, causing, in many cases, the probability class to become an arithmetic class in which only formulas are applied, mechanically and with no meaning. Accordingly, we see no use of technological resources, a low use of physical materials, and a predominance of solving decontextualised exercises. In agreement with several authors [31,33-37], we conclude that the practices employed to teach probability have to be enriched by using a multiplicity of resources and contexts, to progressively advance towards a representation of probabilistic knowledge with conventional procedures and notations.

\section{Limitations of This Study}

A limitation of this study is that the analysis focuses on the knowledge that the eight teachers who make up the study case manifest when teaching probability in primary education; therefore, the results presented here are local since they are limited to Chile, and more specifically to teachers who work in different institutions in the southern part of Chile. However, as far as we know, there are no similar studies for this educational level in Chile. Therefore, we believe that the findings in this study open the way to investigate the knowledge that teachers use when teaching probability.

On the other hand, the sample size is small, and it is true that analysing the teaching practices of eight teachers is not enough to make generalisations about the knowledge used when teaching probability. However, based on the results of this study it is possible to have a first approximation to this knowledge, showing clear patterns regarding the characteristics of the probabilistic tasks implemented by these teachers.

Other limitations are those related to the data. Although the data were collected a few years ago, the stability that teachers show in their teaching practices due to scarce continuous training about probability in Chile, makes it that such data related to their teaching practices have not changed significantly.

\section{Future Recommendations and Implications}

This study has advanced our understanding of the knowledge that teachers bring into play when teaching probability. Indeed, the results of this study suggest to teacher training institutions the need to strengthen mathematical knowledge for teaching probability to primary education teachers through, for example, teacher training programs that consider the 
different dimensions and components that characterise the effective teaching of probability from the earliest ages [9]. Consequently, future studies will investigate how the remaining dimensions and components of the model proposed by Vásquez et al. [9] are manifested in the teaching practices of in-service teachers. This will undoubtedly contribute to exploring and analysing exhaustively the aspects of mathematical knowledge to teach probability that are manifested and observable in teaching practices. Obtaining results with theoretical and empirical foundations will allow giving concrete guidelines to teachers' educators in relation to the mathematical knowledge that primary education teachers need to teach probability. This will benefit all in a world where the teaching of probability is gaining more and more relevance in a changing era full of uncertainty which we must know how to interpret.

Author Contributions: Conceptualization, C.V. and Á.A.; methodology, C.V. and Á.A.; software, C.V.; validation, C.V. and Á.A.; formal analysis, C.V. and Á.A.; investigation, C.V.; resources, C.V.; data curation, C.V.; writing—original draft preparation, C.V. and Á.A.; writing-review and editing, C.V. and Á.A.; visualization, C.V.; supervision, C.V.; project administration, C.V.; funding acquisition, C.V. All authors have read and agreed to the published version of the manuscript.

Funding: Work was carried out within the framework of the FONDECYT project No. 1200356 and project FONDECYT project No. 11150412, both financed by the National Research and Development Agency of the Government of Chile.

Institutional Review Board Statement: Not applicable.

Informed Consent Statement: Informed consent was obtained from all subjects involved in this research.

Data Availability Statement: Data available on request due to restrictions.

Conflicts of Interest: The authors declare no conflict of interest.

\section{References}

1. Shulman, L.S. Knowledge and teaching: Foundations of the new reform. Harv. Educ. Rev. 1987, 57, 1-22. [CrossRef]

2. Hoover, M. Commentary on Section 1: Mounting Progress on Understanding Mathematics Teacher Content Knowledge. In Research Trends in Mathematics Teacher Education; Lo, J.J., Leatham, K.R., Van Zoest, L.R., Eds.; Springer: Berlin/Heidelberg, Germany, 2014; pp. 83-90.

3. Jaworski, B. Mathematics teacher educator learning and development. In The Mathematics Teacher Educator as a Developing Professional; Handbook of Mathematics Teacher Education; Jaworski, B., Wood, T., Eds.; Sense Publishers: Rotterdam, The Netherlands, 2008; pp. 1-13. [CrossRef]

4. Schleicher, A. Desafíos para PISA. RELIEVE 2016, 22, 1-8. [CrossRef]

5. Even, R.; Ball, D.L. (Eds.) The Professional Education and Development of Teachers of Mathematics-The 15th ICMI Study; Springer: Berlin/Heidelberg, Germany, 2009. [CrossRef]

6. Korthagen, F.A. Linking Practice and Theory. The Pedagogy of Realistic Teacher Education; Lawrence Erlbaum Associates: Mahwah, NJ, USA, 2001.

7. Alsina, Á. El Enfoque de los Itinerarios de Enseñanza de las Matemáticas: ¿por qué?, ¿para qué? y ¿cómo aplicarlo en el aula? Tangram 2020, 3, 127-159. [CrossRef]

8. Gal, I. Developing probability literacy: Needs and pressures steeming from frameworks of adult competencies and mathematics curricula. In Proceedings of the 12th International Congress on Mathematical Education; Cho, S.J., Ed.; Springer: Berlin/Heidelberg, Germany, 2012; pp. 1-7.

9. Vásquez, C.; Alsina, Á.; Pincheira, N.; Gea, M.M.; Chandia, E. Una primera aproximación a la caracterización de un modelo para una enseñanza eficaz de la probabilidad a partir de las primeras edades. In Actas del Tercer Congreso Internacional Virtual de Educación Estadística; Contreras, J.M., Gea, M.M., López-Martín, M.M., Eds.; Molina-Portillo: Granada, Spain, 2019; Available online: www.ugr.es/local/fqm126/civeest.html (accessed on 1 March 2019).

10. Vásquez, C.; Alsina, Á.; Pincheira, N.; Gea, M.M.; Chandia, E. Construcción y Validación de un instrumento de observación de clases de probabilidad. Enseñanza Cienc. 2020, 38, 25-43. [CrossRef]

11. Batanero, C.; Godino, J.D.; Roa, R. Training teacher to teach probability. J. Stat. Educ. 2004, 12. [CrossRef]

12. Groth, R.; Meletiou-Mavrotheris, M. Research on Statistics Teachers' Cognitive and Affective Characteristics. In International Handbook of Research in Statistics Education; Ben-Zvi, D., Makar, K., Garfield, J., Eds.; Springer: Berlin/Heidelberg, Germany, 2018; pp. 327-355. [CrossRef] 
13. Da Ponte, J.P.; Noll, J. Building Capacity in Statistics Teacher Education. In International Handbook of Research in Statistics Education; Springer International Handbooks of Education; Ben-Zvi, D., Makar, K., Garfield, J., Eds.; Springer: Berlin/Heidelberg, Germany, 2018. [CrossRef]

14. Moore, D. New pedagogy and new content: The case of statistics. Int. Stat. Rev. 1997, 65, 123-137. [CrossRef]

15. Godino, J.D.; Batanero, C.; Flores, P. El análisis didáctico del contenido matemático como recurso en la formación de profesores. In Homenaje al Profesor Oscar Sáenz Barrio; Departamento de Didáctica y Organización Escolar de la Universidad de Granada: Granada, Spain, 1999; pp. 165-185.

16. Godino, J.D.; Batanero, C.; Wilhelmi, M. Assessing and Developing Pedagogical Content and Statistical Knowledge of primary school teachers through project work. In Joint ICMI/IASE Study: Teaching Statistics in School Mathematics. Challenges for Teaching and Teacher Education, Proceedings of the ICMI Study 18 and 2008 IASE Round Table Conference (Números 1-6), Monterrey, Mexico, 30 June-4 July 2008; Batanero, C., Burrill, G., Reading, C., Rossman, A., Eds.; ICMI; IASE; Available online: https:/ / www.semanticscholar.org/paper / ASSESSING-AND-DEVELOPING-PEDAGOGICAL-CONTENT-AND-OF-GodinoBatanero/2718f7fe35cbafd871f8e91e836e62f4c5e97238 (accessed on 5 September 2021).

17. Godino, J.D.; Ortiz, J.; Roa, R.; Wilhelmi, M. Models for Statistical Pedagogical Knowledge. In Teaching Statistics in School Mathematics—Challenges for Teaching and Teacher Education. A Joint ICMIIASE Study; Batanero, C., Burrill, G., Reading, C., Eds.; Springer: Berlin, Germany, 2011; pp. 271-282. [CrossRef]

18. Burgess, T. A framework for examining teacher knowledge as used in action while teaching statistics. In Working Cooperatively in Statistics Education, Proceedings of the Seventh International Conference on Teaching Statistics (ICOTS7), Salvador, Brazil, 2-7 July 2006; Rossman, A., Chance, B., Eds.; pp. 1-6. Available online: https:/ / citeseerx.ist.psu.edu/viewdoc/download?doi=10.1.1.450.9047\& rep=rep1\&type $=$ pdf (accessed on 5 September 2021).

19. Burgess, T. Teacher knowledge and statistics: What types of knowledge are used in the primary classroom? Math. Enthus. 2009, 6, $3-24$.

20. Burgess, T. Teacher Knowledge of and for Statistical Investigations. In Teaching Statistics in School Mathematics: Challenges for Teaching and Teacher Education. A Joint ICMI/IASE Study; Batanero, C.G., Burrill, C., Eds.; Springer: Berlin/Heidelberg, Germany, 2011; pp. 259-270.

21. Burgess, T. How Does Teacher Knowledge in Statistics Impact on Teacher Listening? In Mathematics Education: Expanding Horizons, Proceedings of the 35th Annual Conference of the Mathematics Education Research Group of Australasia (MERGA), Singapore, 2-6 July 2012; Dindyal, J., Cheng, L.P., Fong Ng, S., Eds.; pp. 146-153. Available online: https://files.eric.ed.gov/fulltext/ED573184.pdf (accessed on 5 September 2021).

22. Ball, D.L.; Thames, M.H.; Phelps, G. Content knowledge for teaching: What makes it special? J. Teach. Educ. 2008, 59, 389-407. [CrossRef]

23. Wild, C.; Pfannkuch, M. Statistical Thinking in Empirical Enquiry. Int. Stat. Rev. 1999, 67, 223-248. [CrossRef]

24. Lee, H.; Hollebrands, K. Preparing to Teach Mathematics with Technology: An Integrated Approach to Developing Technological Pedagogical Content Knowledge. Contemp. Issues Technol. Teach. Educ. 2008, 8, 326-341.

25. Lee, H.; Hollebrands, K. Teaching Statistics in School Mathematics-Challenges for Teaching and Teacher Education. In Teaching Statistics in School Mathematics: Challenges for Teaching and Teacher Education. A Joint ICMI/IASE Study; Batanero, C., Burrill, G., Reading, C., Eds.; Springer: Berlin/Heidelberg, Germany, 2011; pp. 359-369.

26. Garfield, J.; Ben-Zvi, D. Developing Students' Statistical Reasoning. Connecting Research and Teaching Practice; Springer Science \& Business Media: Berlin/Heidelberg, Germany, 2008.

27. Garfield, J.; Ben-Zvi, D. Helping Students Develop Statistical Reasoning: Implementing a Statistical Reasoning Learning Environment. Teach. Stat. 2009, 31, 72-77. [CrossRef]

28. Pfannkuch, M.; Ben-Zvi, D. Developing Teachers' Statistical Thinking. In Teaching Statistics in School Mathematics: Challenges for Teaching and Teacher Education A Joint ICMIIASE Study; Batanero, C., Burrill, G., Reading, C., Eds.; Springer: Berlin/Heidelberg, Germany, 2011; pp. 323-333.

29. Ben-Zvi, D.; Gravemeijer, K.; Ainley, J. Design of Statistics Learning Environments. In International Handbook of Research in Statistics Education; Ben-Zvi, D., Makar, K., Garfield, J., Eds.; Springer: Berlin/Heidelberg, Germany, 2018; pp. 473-502.

30. Ball, D.L.; Forzani, F.M. Building a common core for learning to teach and connecting professional learning to practice. Am. Educ. 2011, 35, 17-21.

31. Alsina, Á.; Vásquez, C.; Muñiz-Rodríguez, L.; Rodríguez-Muñiz, L.J. ¿Cómo promover la alfabetización estadística y probabilística en contexto? Estrategias y recursos a partir de la COVID-19 para Educación Primaria. Épsilon 2020, 104, 99-128.

32. Vásquez, C.; Ruz, F.; Martínez, M.V. Recursos virtuales para la enseñanza de la estadística y la probabilidad: Un aporte para la priorización curricular chilena frente a la pandemia de la COVID-19. TANGRAM 2020, 3, 159-183. [CrossRef]

33. Vásquez, C.; Alsina, Á. Lenguaje probabilístico: Un camino para el desarrollo de la alfabetización probabilística. Un estudio de caso en el aula de Educación Primaria. BOLEMA 2017, 31, 454-478. [CrossRef]

34. Batanero, C.; Díaz, C. El papel de los proyectos en la enseñanza y aprendizaje de la estadística. In Aspectos Didácticos de Las Matemáticas; Royo, J.P., Ed.; ICE: London, UK, 2004; pp. 125-164.

35. Batanero, C. Recursos en Internet para la educación estadística. UNO 1998, 15, 13-25. 
36. Batanero, C. La comprensión de la probabilidad en los niños. ¿Qué podemos aprender de la investigación? In Atas do III Encontro de Probabilidades e Estatítica na Escola; Fernandes, J.A., Correia, P.F., Martinho, M.H., Viseu, F., Eds.; Centro de Investigação em Educação, Universidade Do Minho: Braga, Portugal, 2013.

37. Godino, J.D.; Batanero, C.; Cañizares, M.J. Azar y Probabilidad. Fundamentos Didácticos y Propuestas Curriculares; Editorial Síntesis: Madrid, Spain, 1987.

38. Batanero, C. Razonamiento probabilístico en la vida cotidiana: Un desafío educativo. In Investigación en el Aula de Matemáticas. Estadística y Azar [CD ROM]; Flores, P., Lupiáñez, J., Eds.; Sociedad de Educación Matemática Thales: Granada, Spain, 2006; ISBN 84-688-0573-4.

39. Hahn, C. Linking academic knowledge and professional experience in using statistics: A design experiment for business school students. Educ. Stud. Math. 2014, 86, 239-251. [CrossRef]

40. Cobb, G.; Moore, D. Mathematics, Statistics, and Teaching. Am. Math. Mon. 1997, 104, 801-823. [CrossRef]

41. Lopéz-Martín, M.M.; Contreras, J.M.; Carretero, M.; Serrano, L. Análisis de los problemas de probabilidad propuestos en las pruebas de acceso a la Universidad en Andalucía. AIEM 2016, 9, 65-84. [CrossRef]

42. Stein, M.K.; Smith, M.; Henningsen, M.; Silver, E. Implementing Standards-Based Mathematics Instruction: A Casebook for Professional Development; Teachers College Press: New York, NY, USA, 2009.

43. Stein, M.K.; Grover, B.W.; Henningsen, M. Building Student Capacity for Mathematical Thinking and Reasoning: An Analysis of Mathematical Tasks Used in Reform Classrooms. Am. Educ. Res. J. 1996, 33, 455-488. [CrossRef]

44. Smith, M.S.; Stein, M.K. Selecting and creating mathematical tasks: From Research to Practice. Math. Teach. Middle Sch. 1998, 3, 344-350. [CrossRef]

45. NCTM. Principles to Action: Ensuring Mathematical Success for All; NCTM: Reston, VA, USA, 2014.

46. Gómez-Torres, E.; Batanero, C.; Contreras, J.M. Procedimientos probabilísticos en libros de texto de matemáticas para educación primaria en España. Épsilon 2014, 31, 25-42.

47. Vásquez, C.; Alsina, Á. Intuitive ideas about chance and probability in children from 4 to 6 years old. Acta Sci. 2019, 21, 131-154. [CrossRef]

48. Batanero, C. Significados de la probabilidad en la educación secundaria. RELIME 2005, 8, 247-264.

49. Batanero, C.; Henry, M.; Parzysz, B. The nature of chance and probability. In Exploring Probability in School: Challenges for Teaching and Learning; Jones, G., Ed.; Springer: Berlin/Heidelberg, Germany, 2005; pp. 15-37.

50. Yin, R. Case Study Research. Design and Methods; Sage: New York, NY, USA, 2009.

51. Bisquerra, R. Metodología de la Investigación Educativa; Editorial La Muralla: Madrid, Spain, 2019.

52. Mercer, N. The analysis of classroom talk: Methods and methodologies. Br. J. Educ. Psychol. 2010, 80, 1-14. [CrossRef]

53. Chapin, S.; O'Connor, C.; Canavan, N. Classroom Discussions in Math.: A Teacher's Guide for Using Talk Moves to Support. The Common Core and More, Grades K-6, 3rd ed.; Scholastic, Inc.: New York, NY, USA, 2013.

54. Stylianides, G.J. Reasoning-and-proving in school mathematics textbooks. Math. Think. Learn. 2009, 1, 258-288. [CrossRef]

55. Vásquez, C.; Alsina, Á. Aproximación al conocimiento común del contenido para enseñar probabilidad desde el modelo del conocimiento didáctico-matemático. Educ. Matemática 2017, 29, 79-108. [CrossRef]

56. Bargagliotti, B.; Franklin, C.; Arnold, P.; Gould, R.; Jhonson, R.; Perez, L.; Spangles, D.A. (Eds.) Pre-K-12 Guidelines for Assessment and Instruction in Statistics Education II (GAISE II); American Statistical Association: Alexandria, VA, USA, 2020.

57. Mullis, V.S.I.; Martin, M.O.; Foy, P.; Kelly, D.L.; Fishbein, B. TIMSS 2019 International Report; TIMSS \& PIRLS International Study Center, Lynch School of Education and Human Development, Boston College and International Association for the Evaluation of Educational Achievement (IEA): Boston, MA, USA, 2019. 